\title{
Expression of FOXL2 in human normal pituitaries and pituitary adenomas
}

\author{
Noboru Egashira ${ }^{1}$, Susumu Takekoshi ${ }^{2}$, Mao Takei ${ }^{3}$, Akira Teramoto $^{3}$ and Robert Y Osamura ${ }^{4}$ \\ ${ }^{1}$ Parhology and Genetic Testing Section, Hamura Laboratory, SRL, Tokyo, Japan; ${ }^{2}$ Department of Pathology, \\ Tokai University School of Medicine, Kanagawa, Japan; ${ }^{3}$ Department of Neurosurgery, Nippon Medical \\ School, Tokyo, Japan and ${ }^{4}$ Center for Diagnostic Pathology International University of Health and Welfare \\ Mita Hospital, Tokyo, Japan
}

\begin{abstract}
Many transcription factors have important roles in the function and differentiation of the human pituitary adenomas. Forkhead box gene transcription factor L2, Fox12, is expressed during mouse pituitary development and co-localizes with the expression of $\alpha$-glycoprotein hormone subunit ( $\alpha \mathrm{GSU})$. In addition, Foxl2 regulates expression of the $\alpha \mathrm{GSU}$ gene ( $\mathrm{Cga}$ ) in cell culture. To elucidate the functional role of FOXL2 in the human pituitary, we examined the expression and localization of FOXL2 in normal human pituitaries and various types of pituitary adenomas. Human pituitary adenomas were obtained by trans-sphenoidal surgery from 67 patients. Three normal adult pituitaries were obtained from autopsies of non-endocrine cases. The localization of FOXL2 and pituitary hormones in these pituitary patients was examined by immunohistochemical staining and RT-PCR. Quantitative analysis of FOXL2 protein was performed by immunoblotting. FOXL2 was localized in the nuclei of $\sim 20 \%$ of normal pituitary cells that also co-expressed gonadotropins including follicule-stimulating hormone $\beta(\mathrm{FSH} \beta)$, luteinizing hormone $\beta(\mathrm{LH} \beta)$, and $\alpha \mathrm{GSU}$, whereas it was observed in minor proportion of thyroid-stimulating hormone (TSH)-producing cells, prolactin (PRL)-producing cells, and precursor of adrenocorticotropic hormone (ACTH)-producing cells. FOXL2 immunoreactivity was not detected in growth hormone (GH)-producing cells or S100-positive folliculo-stellate cells. In human pituitary adenomas, FOXL2 was expressed in the nuclei of the adenoma cells. FOXL2 was detected in 13 of 15 gonadotropin-subunitproducing adenoma (Gn-oma) cases and 8 of 11 null cell adenoma cases, but its incidence was reduced or not detected in the other types of adenomas. The results of this study suggest that FOXL2 contributes to the human-specific functional expression and the differentiation of gonadotroph cells and adenomas. Modern Pathology (2011) 24, 765-773; doi:10.1038/modpathol.2010.169; published online 8 April 2011
\end{abstract}

Keywords: FOXL2; gonadotropes; pituitary

Factors that are important for pituitary organogenesis exist as exogenous and endogenous signaling gradients. The pituitary gland develops from Rathke's pouch, and the pituitary primordium appears on embryonic day (E) 8.5 in mice. The hormone-producing cells of the pituitary gland appear initially as $\alpha$-glycoprotein hormone subunit ( $\alpha \mathrm{GSU}$ ) positive cells on E11 and, subsequently, differentiate into anterior pituitary hormone-producing cells. ${ }^{1}$ The pituitary cell types can be classified into three cell lineages: the growth hormone (GH)-prolactin (PRL)-thyroid-stimulating

Correspondence: Dr RY Osamura, MD, PhD, Center for International University of Health and Welfare Graduate School, 1-4-3 Mita, Minato-ku, Tokyo 108-8329, Japan.

E-mail: osamura@iuhw.ac.jp

Received 28 January 2010; revised 17 June 2010; accepted 18 June 2010; published online 8 April 2011 hormone (TSH) (GH-PRL-TSH) cell lineage, the proopiomelanocortin (precursor of adrenocorticotropic hormone, ACTH) lineage, and the gonadotropin (luteinizing hormone/follicle-stimulating hormone; LH/FSH) lineage. Several transcription factors are known to regulate pituitary development, proliferation, and the functional differentiation of these lineages. Pitx1, Pitx2, Lhx3, Lhx4, and Rpx/Hesx 1 are expressed in early pituitary development, and are essential for normal pituitary organogenesis. ${ }^{2-6}$ On the other hand, late functional transcription factors, including Tpit, Gata2, Sf1, Egr1, Estrogen receptor (Esr1), and $Z n-15$, regulate the functional differentiation of each type of hormone-producing cell. ${ }^{7-12}$ Forkhead factors are a class of transcription factors that are important for diverse developmental processes. Deficiencies of individual forkhead genes may result in 
deficiency of speech and language, diabetes, immunodeficiency, cleft palate, and eye development disorders. ${ }^{13-16}$ One member of the forkhead family, Foxl2, is expressed in the eye, the ovary and the pituitary. In putative Foxl2 knockout animals, eye lids are not formed completely, and the ovary does not mature and lack proliferating cells. ${ }^{17}$ In humans, FOXL2 has been shown to be mutated in type Iblepharophimosis/ptosis/epicanthus inversus syndrome (BPES). ${ }^{18}$ Type I BPES is also associated with eyelid abnormalities and premature ovarian failure (POF).

Kioussi et a $1^{19}$ reported that Foxl2, also known as pituitary forkhead factor, is expressed in the developing pituitary gland. However, key questions remain concerning the onset of expression, the types of pituitary cells that express Foxl2, and its upstream regulators. Previously, we established the position of Foxl2 in the genetic hierarchy of pituitary development. Foxl2 is co-localized with $\alpha$ GSU only in quiescent cells of the mouse pituitary from E11.5 through adulthood and regulates the $\alpha \mathrm{GSU}$ promoter (Cga promoter) in cell culture. ${ }^{20}$

In contrast to the studies of Foxl2 in the development of mouse pituitary, there have been no extensive studies on FOXL2 expression in human normal pituitaries and in adenomas. This study aimed to elucidate whether the FOXL2 expression is related to functional differentiation in human pituitaries. Our present study deals with the localization of FOXL2 in human pituitaries and various types of adenomas. Our results suggest a novel role for FOXL2 in human pituitaries.

\section{Materials and methods}

\section{Clinical Characteristics of Human Pituitary Specimens}

Specimens of pituitary adenomas were obtained at the time of trans-sphenoidal surgery from 67 patients at the Nippon Medical School and its affiliated hospitals. Three normal pituitaries were obtained at autopsy from adult individuals without pituitary disorders. Pituitary adenomas were classified on the basis of clinical and biological findings, including the baseline hormone and dynamic testing. The clinical and endocrinologic features were as follows: 19 patients with GH-producing adenomas and symptoms of acromegaly; 9 PRL-producing adenomas; 8 ACTH-producing adenomas and typical Cushing's syndrome; 5 TSH-producing adenomas; 26 non-functioning adenomas that presented no clinical evidence of anterior pituitary hormone excess and did not show high serum concentrations of any of the anterior pituitary hormone except mild hyperprolactinemia $(<100 \mathrm{ng} / \mathrm{ml})$ and included 11 null cell adenomas (hormone immunonegative) and 15 gonadotropin-subunit-producing adenomas. These adenomas were classified based on their clinical manifestation, biological function, and morphology including immunohistochemistry and ultrastructure.

\section{FOXL2 and Pituitary Hormones Immunohistochemistry}

The pituitary glands from the patients were fixed overnight in $20 \%$ formalin at $4{ }^{\circ} \mathrm{C}$. The fixed tissues were washed in PBS and dehydrated through an ethanol series and embedded in paraffin. Tissue sections of $2 \mu \mathrm{m}$ thickness were prepared for immunohistochemistry. Slides were dewaxed and rehydrated before staining. For FOXL2 immunostaining, epitopes were exposed by autoclaving for $5 \mathrm{~min}$ in $10 \mathrm{mM}$ citric acid (pH 6.0). Anti-FOXL2 antibody (abcam, Cambridge, UK) was used at a 1:200 dilution. Anti-PRL (NHPP, NIDDK, Bethesda, MD, USA), anti-human GH (DAKO cytomation, Denmark), and anti-human $\alpha \mathrm{GSU}$ (NHPP) rabbit antibodies were used at 1:600, 1:400, and 1:100, respectively. Antihuman LH $\beta$ and FSH $\beta$ (Immunotech, Marseille, France), anti-human TSH $\beta$ (Advanced Immunochemical, Long Beach, CA, USA), and anti-human ACTH (DAKO Cytomation) monoclonal antibodies were used at 1:200, 1:100, and 1:200, respectively. Anti-cow S100 polyclonal antibody (DAKO Cytomation) was used at 1:100. Sections were incubated with these primary antibodies for $60 \mathrm{~min}$ at room temperature, followed by incubation in biotin-conjugated secondary antibodies (Jackson ImmunoResearch, West Grove, PA, USA). Signals were amplified using the Avidin-biotin peroxidase complex method (Vector Laboratories, Burlingame, CA, USA) according to

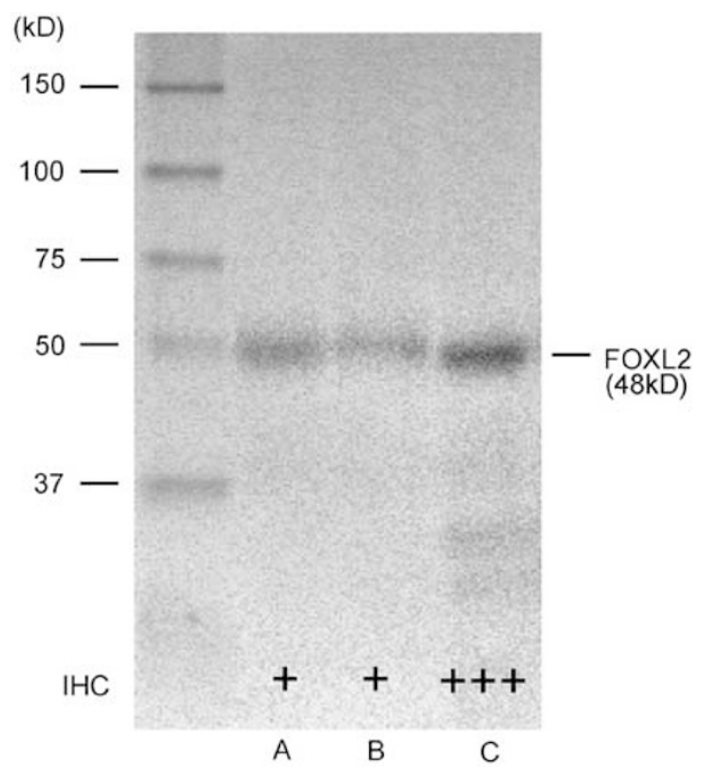

Figure 1 FOXL2 expression levels were correlated with FOXL2 immunoreactivities. The expression levels of FOXL2 protein was examined by immunoblotting. The quantities of FOXL2 protein were correlated with the frequencies of FOXL2 immunoreactivity in pituitary adenomas. IHC; the results of immunohistochemical analysis of FOXL2 expression from Table 2. (A) Gonadotropinoma case 9; (B) null cell adenoma case 8; (C) gonadotropinoma case 4. 

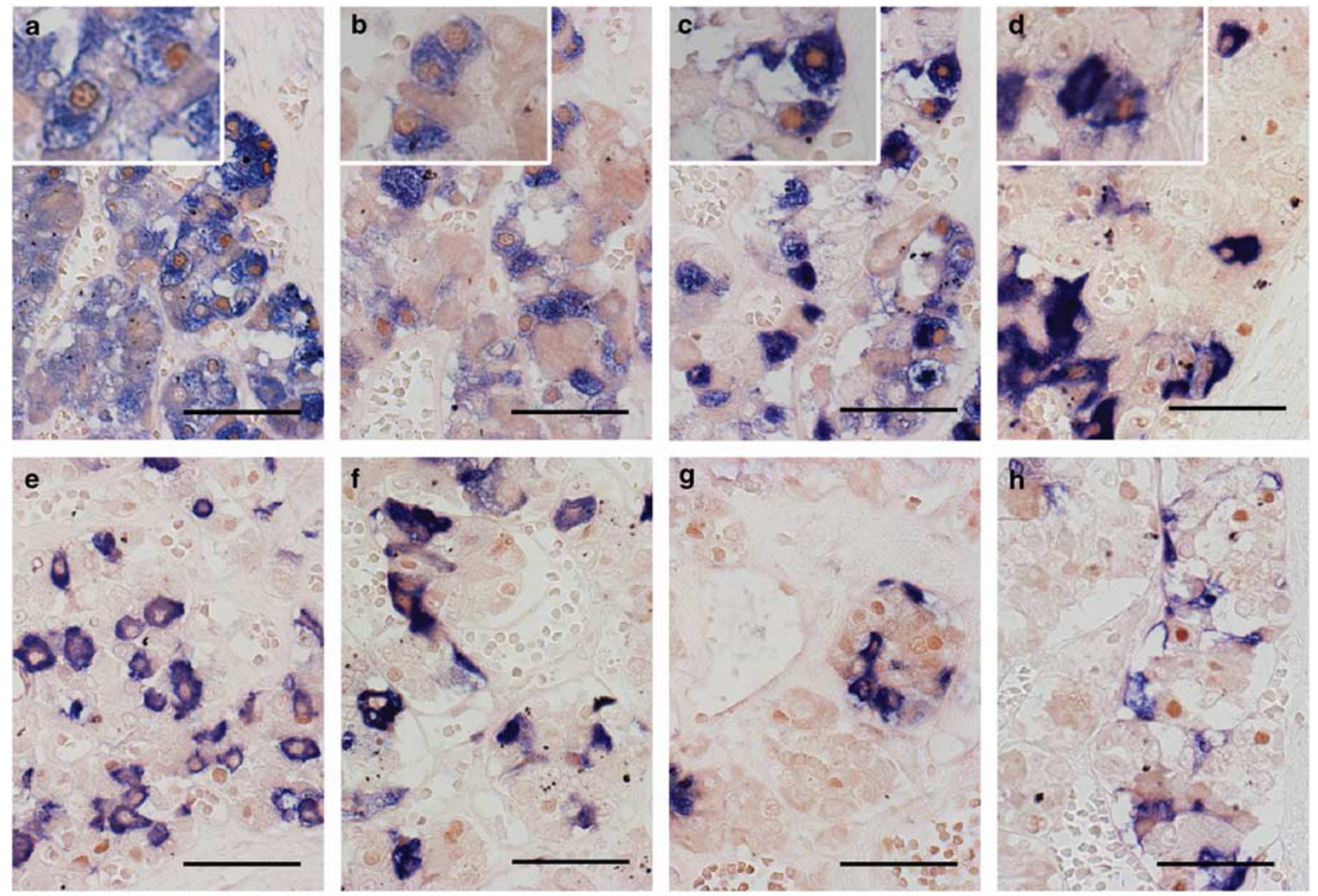

Figure 2 Expression of FOXL2 as shown by double-immunohistochemical staining in human normal pituitary glands. Expression of FOXL2 protein is observed in the nuclei of anterior pituitary cells as a brown color. The immunoreactivities of pituitary hormones and S100 protein are shown as a blue color. FOXL2 immunoreactivity was localized mainly in gonadotroph cells $(\mathbf{a}, \alpha \mathrm{GSU} ; \mathbf{b}, \mathrm{FSH} \beta ; \mathbf{c}, \mathrm{LH} \beta)$ and a small fraction of (d) TSH $\beta$-positive cells (arrow heads). The immunoreactivity was observed rarely in (e) GH-producing cells, (f) PRL-producing cells, (g) ACTH-producing cells, and (h) S100-positive folliculo-stellate cells. Bar, $50 \mu \mathrm{m}$.

the manufacturer's instructions. Peroxidase activity was visualized with 3,3'-diaminobenzidine (DAKO Cytomation, Glostrup, Denmark), and the sections were lightly counterstained with methyl green. Immunohistochemical specificity of all the antibodies was confirmed by non-immune immunoglobulins or normal serum as negative controls.

\section{Immunoblotting for FOXL2 Protein in Pituitary Adenomas}

Tissue aliquots were snap frozen in liquid nitrogen for immunoblot analysis. Pituitary tumor tissue protein extracts were prepared in $\beta$-mercaptoethanol containing sample buffer and resolved under reducing conditions on $10 \%$ SDS-polyacrylamide gels using standard methods. Resolved proteins were transferred to nitrocellulose membranes and probed with antibodies against FOXL2 (1:2000; abcam) overnight at $4{ }^{\circ} \mathrm{C}$. After washing, membranes were incubated with appropriate IgG-HRP conjugates, and immunoreactive protein bands were visualized with ECL plus (GE Healthcare UK, Buckinghamshire, UK). Total protein was normalized by tissue weight or
Ponceau S staining, and protein bands were quantified by densitometry (Video Densitometer model 620; Bio-Rad Laboratories, Hercules, CA, USA).

\section{RT-PCR Analysis of FOXL2 mRNA Expression from FFPE Samples}

All paraffin blocks were cut on the same microtome with single use disposable blades. Briefly, five $7 \mu \mathrm{m}$ sections of stored formalin-fixed paraffin-embedded (FFPE) pituitary adenoma tissues were deparaffinized in xylene at $50{ }^{\circ} \mathrm{C}$, followed by washes in ethanol. Total RNA was extracted by RecoverAll Total Nucleic Acid Isolation kit (Ambion, Austin, TX, USA). RNA was reverse transcribed using the SuperScript III First-Strand Synthesis System RTPCR kit (Invitrogen Life Technologies, CA, USA) after incubation with proteinase $\mathrm{K}$. RNase inhibitor (RNaseOUT) and random primer were also from Invitrogen Life Technologies.

A normal pituitary cDNA was purchased from BioChain Institute (Hayward, CA, USA) as a FOXL2positive control. PCR was performed using the AmpliTaq Gold PCR kit (Applied Biosystems, Foster 
Table 1 The expression of FOXL2 protein in anterior pituitary-hormone-producing cells and S100 positive cells in human normal pituitaries (expressed as percentage)

\begin{tabular}{|c|c|c|c|c|c|c|c|c|}
\hline & $\alpha G S U$ & $F S H \beta$ & $L H \beta$ & $T S H \beta$ & $G H$ & $P R L$ & ACTH & $S 100$ \\
\hline FOXL2 & $60.50 \pm 0.07$ & $61.30 \pm 3.22$ & $64.80 \pm 0.04$ & $6.39 \pm 0.01$ & ND & $1.77 \pm 0.00$ & $3.83 \pm 0.02$ & ND \\
\hline
\end{tabular}

ND, not detected.

The data are the mean \pm s.d.

Table 2 Results of immunohistochemical analysis for anterior pituitary hormones and FOXL2 in 67 pituitary adenomas

\begin{tabular}{|c|c|c|c|c|c|c|c|c|c|c|}
\hline \multirow[t]{2}{*}{ Diagnosis } & \multirow[t]{2}{*}{ Case no. } & \multirow[t]{2}{*}{ Age/sex } & \multicolumn{8}{|c|}{ Immunohistochemistry } \\
\hline & & & $G H$ & $P R L$ & ACTH & $T S H \beta$ & $L H \beta$ & $F S H \beta$ & $\alpha G S U$ & FOXL2 \\
\hline \multirow[t]{11}{*}{ Null cell adenomas } & 1 & $46 / \mathrm{M}$ & - & - & - & - & - & - & - & +++ \\
\hline & 2 & $75 / \mathrm{M}$ & - & - & - & - & - & - & - & +++ \\
\hline & 3 & $71 / \mathrm{M}$ & - & - & - & - & - & - & - & +++ \\
\hline & 4 & $65 / \mathrm{M}$ & - & - & - & - & - & - & - & ++ \\
\hline & 5 & $45 / F$ & - & - & - & - & - & - & - & $+/-$ \\
\hline & 6 & $66 / F$ & - & - & - & - & - & - & - & $+/-$ \\
\hline & 7 & $56 / \mathrm{M}$ & - & - & - & - & - & - & - & $+1-$ \\
\hline & 8 & $51 / \mathrm{F}$ & - & - & - & - & - & - & - & + \\
\hline & 9 & $45 / F$ & - & - & - & - & - & - & - & - \\
\hline & 10 & $41 / \mathrm{F}$ & - & - & - & - & - & - & - & - \\
\hline & 11 & $52 / \mathrm{F}$ & - & - & - & - & - & - & - & - \\
\hline \multirow{15}{*}{$\begin{array}{l}\text { Gonadotropin-subunit- } \\
\text { positive adenomas }\end{array}$} & 1 & $50 / \mathrm{M}$ & - & - & - & - & - & + & + & +++ \\
\hline & 2 & $52 / \mathrm{M}$ & - & - & - & - & - & + & + & +++ \\
\hline & 3 & $71 / \mathrm{F}$ & - & - & - & - & - & - & + & +++ \\
\hline & 4 & $64 / \mathrm{M}$ & - & - & - & - & + & ++ & + & +++ \\
\hline & 5 & 79/M & - & - & - & - & - & + & + & +++ \\
\hline & 6 & $31 / \mathrm{M}$ & - & - & - & - & - & + & - & +++ \\
\hline & 7 & $53 / \mathrm{M}$ & - & - & - & - & - & ++ & + & ++ \\
\hline & 8 & $56 / F$ & - & - & - & - & - & + & $+/-$ & ++ \\
\hline & 9 & $63 / \mathrm{M}$ & - & - & - & - & ++ & +++ & +++ & + \\
\hline & 10 & $51 / \mathrm{F}$ & - & - & - & - & - & $+1-$ & $+1-$ & + \\
\hline & 11 & $60 / \mathrm{M}$ & - & - & - & - & - & ++ & - & + \\
\hline & 12 & $61 / F$ & - & - & - & - & + & ++ & - & + \\
\hline & 13 & $35 / F$ & - & - & - & - & - & + & + & $+1-$ \\
\hline & 14 & $39 / F$ & - & - & - & - & - & + & + & - \\
\hline & 15 & $36 / F$ & - & - & - & - & + & + & - & - \\
\hline \multirow[t]{5}{*}{ TSH-producing adenomas } & 1 & $40 / \mathrm{M}$ & - & - & - & +++ & - & - & +++ & $+1-$ \\
\hline & 2 & M & + & - & + & +++ & $+/-$ & - & + & $+/-$ \\
\hline & 3 & $53 / \mathrm{F}$ & + & + & - & +++ & - & - & ++ & - \\
\hline & 4 & $62 / \mathrm{F}$ & + & - & - & + & - & - & ++ & - \\
\hline & 5 & $57 / F$ & - & - & - & +++ & - & - & - & - \\
\hline \multirow[t]{19}{*}{ GH-producing adenomas } & 1 & $47 / \mathrm{M}$ & +++ & ++ & ++ & + & - & - & ++ & + \\
\hline & 2 & $56 / F$ & +++ & +++ & - & - & - & - & $+1-$ & $+1-$ \\
\hline & 3 & $57 / \mathrm{F}$ & +++ & - & - & - & - & - & +++ & - \\
\hline & 4 & $55 / F$ & +++ & + & - & - & - & - & + & - \\
\hline & 5 & $56 / F$ & +++ & +++ & - & - & - & - & +++ & - \\
\hline & 6 & $66 / F$ & +++ & +++ & - & - & - & - & +++ & - \\
\hline & 7 & $38 / F$ & +++ & ++ & - & - & - & - & + & - \\
\hline & 8 & $46 / F$ & +++ & ++ & - & - & - & - & +++ & - \\
\hline & 9 & $52 / \mathrm{F}$ & +++ & + & - & - & - & - & - & - \\
\hline & 10 & $58 / \mathrm{M}$ & ++ & + & - & - & - & - & ++ & - \\
\hline & 11 & $43 / F$ & +++ & + & - & - & - & - & - & - \\
\hline & 12 & $58 / \mathrm{M}$ & ++ & - & - & - & - & - & + & - \\
\hline & 13 & $60 / \mathrm{F}$ & +++ & + & - & - & - & - & - & - \\
\hline & 14 & $28 / F$ & +++ & + & - & - & - & - & - & - \\
\hline & 15 & $41 / F$ & ++ & ++ & - & - & - & - & + & - \\
\hline & 16 & $46 / \mathrm{M}$ & +++ & +++ & - & - & - & - & - & - \\
\hline & 17 & $22 / \mathrm{M}$ & +++ & ++ & - & - & - & - & - & - \\
\hline & 18 & $70 / \mathrm{F}$ & +++ & +++ & - & - & - & - & - & - \\
\hline & 19 & $42 / \mathrm{F}$ & +++ & - & - & - & - & - & - & - \\
\hline
\end{tabular}


Table 2 Continued

\begin{tabular}{|c|c|c|c|c|c|c|c|c|c|c|}
\hline \multirow[t]{2}{*}{ Diagnosis } & \multirow[t]{2}{*}{ Case no. } & \multirow[t]{2}{*}{ Age/sex } & \multicolumn{8}{|c|}{ Immunohistochemistry } \\
\hline & & & $G H$ & $P R L$ & ACTH & TSH $\beta$ & $L H \beta$ & $F S H \beta$ & $\alpha G S U$ & FOXL2 \\
\hline \multirow[t]{9}{*}{ PRL-producing adenomas } & 1 & $30 / F$ & $+/-$ & + & - & - & - & - & - & $+/-$ \\
\hline & 2 & $\mathrm{~F}$ & - & + & - & - & - & - & - & $+1-$ \\
\hline & 3 & $25 / F$ & - & ++ & - & - & - & - & - & - \\
\hline & 4 & $\mathrm{~F}$ & $+1-$ & +++ & - & - & - & - & - & - \\
\hline & 5 & $32 / \mathrm{M}$ & - & +++ & - & - & - & - & - & - \\
\hline & 6 & $30 / \mathrm{M}$ & - & +++ & - & - & - & - & - & - \\
\hline & 7 & $\mathrm{~F}$ & - & +++ & - & - & - & - & - & - \\
\hline & 8 & $63 / \mathrm{F}$ & - & +++ & - & - & - & - & - & - \\
\hline & 9 & $20 / \mathrm{F}$ & - & +++ & - & - & - & - & - & - \\
\hline \multirow[t]{8}{*}{ ACTH-producing adenomas } & 1 & $32 / \mathrm{M}$ & - & - & +++ & - & - & - & ++ & - \\
\hline & 2 & $\mathrm{~F}$ & - & - & ++ & - & - & - & $+1-$ & - \\
\hline & 3 & $28 / \mathrm{F}$ & - & - & +++ & - & - & - & - & - \\
\hline & 4 & $72 / \mathrm{F}$ & - & - & +++ & - & - & - & - & - \\
\hline & 5 & $76 / F$ & - & - & +++ & - & - & - & - & - \\
\hline & 6 & $26 / \mathrm{F}$ & - & - & +++ & - & - & - & - & - \\
\hline & 7 & $72 / \mathrm{F}$ & - & - & +++ & - & - & - & - & - \\
\hline & 8 & $52 / \mathrm{F}$ & - & - & +++ & - & - & - & - & - \\
\hline
\end{tabular}

Minus indicates negative; $+/-,<5 \% ;+, 5-20 \% ;++, 20-50 \% ;+++$, over $50 \%$ of adenoma cells; ND; not done.

FOXL2 immunoreactivity is estimated by frequency.

City, CA, USA) according to the manufacturer's instructions, and each specific primer was as follows: human FOXL2 primers, 5'-GAGTTTTTGT TGGGCCTTCA- $3^{\prime}$ and $5^{\prime}$-GAGGGTGAAACTTCCCC AAT-3'; human $\beta$ Actin primers, $5^{\prime}$-TCCTCAGCAGG ATTTTCACC- $3^{\prime}$ and $5^{\prime}$-CATGTTGGCGTCAAACTT GT-3' . cDNA samples for FOXL2 PCR were incubated for 37 cycles of PCR amplification on a Mastercycler thermal cycler (Eppendorf AG, Hamburg, Germany). The FOXL2 and $\beta$ actin PCR products were detected as bands of 97 and $103 \mathrm{bp}$, respectively. The PCR products were analyzed by electrophoresis with $12 \%$ Acrylamide gel and visualized by ethidium bromide staining. The density of PCR products was measured by CS Analyzer 2.0 (ATTO \& Rise Corporation, Tokyo, Japan).

\section{Results}

The specificity of the anti-FOXL2 antibody was confirmed by immunoblotting (Figure 1). The antiFOXL2 antibody detected a single band at $48 \mathrm{kDa}$. The quantities of FOXL2 protein were correlated with the frequencies of FOXL2 immunoreactivity in pituitary adenomas (Table 2). The localization of FOXL2 was examined by immunodouble staining in three normal pituitaries. The immunoreactivity of FOXL2 protein was observed in the nuclei of the pituitary cells (Figures 2a-h). Table 1 summarizes the expression ratios (expressed as percentage) that were obtained by counting the FOXL2-positive cells among the anterior pituitary hormone-producing cells and S100 protein-positive folliculo-stellate cells. Approximately $20 \%$ of the anterior pituitary cells were FOXL2 positive, and most of the FOXL2positive cells were gonadotropin-subunit-producing cells. In other words, most of the FOXL2-positive cells were also $\mathrm{FSH} \beta / \mathrm{LH} \beta / \alpha \mathrm{GSU}$ positive (Figures 2a-c), whereas FOXL2 immunoreactivity was scarcely observed in PRL- or ACTH-producing cells (Figures $2 \mathrm{f}$ and g). FOXL2 co-localized in many of gonadotropin-subunit-producing cells. However, FOXL2 was detected only in a minority of TSHproducing cells, which were also known as $\alpha \mathrm{GSU}$ expressing cells (Figure 2d). FOXL2 immunoreactivity was not detected in GH-producing cells or S100-positive folliculostellate cells (Figures 2e and $h)$.

In 67 human pituitary adenomas, FOXL2 immunoreactivity was demonstrated in the nuclei of the adenoma cells. The results of the immunohistochemical examination of the different types of adenoma are summarized in Table 2. FOXL2 was detected in 8 of $11(72.7 \%$ ) null cell adenoma cases (Figures 3aA and $3 \mathrm{bA})$ and in 13 of $15(86.7 \%)$ gonadotropinsubunit-producing adenoma cases (Gn-omas) (Figures $3 \mathrm{aB}$ and $3 \mathrm{bG}$ ). These adenomas showed diffuse and strong nuclear reactivity for FOXL2 protein (Figures 3aA and B). However, in 2 of 5 TSHproducing adenomas (TSHomas), some weakly positive $(+/-)$ cells for FOXL2 were observed (Figures $3 \mathrm{aC}$ and $3 \mathrm{bC}$ ). FOXL2 was expressed very rarely in GH-producing adenomas (GHomas), PRLproducing adenomas (PRLomas) (Figures $3 \mathrm{aD}, \mathrm{E}$ and $3 \mathrm{bD}, \mathrm{E})$. FOXL2 was not detected in ACTHproducing adenomas (Figures $3 \mathrm{aF}$ and $\mathrm{bF}$ ).

The mRNA expression for FOXL2 was examined by RT-PCR in 30 human pituitary adenomas that were taken from the same FFPE samples analyzed by 

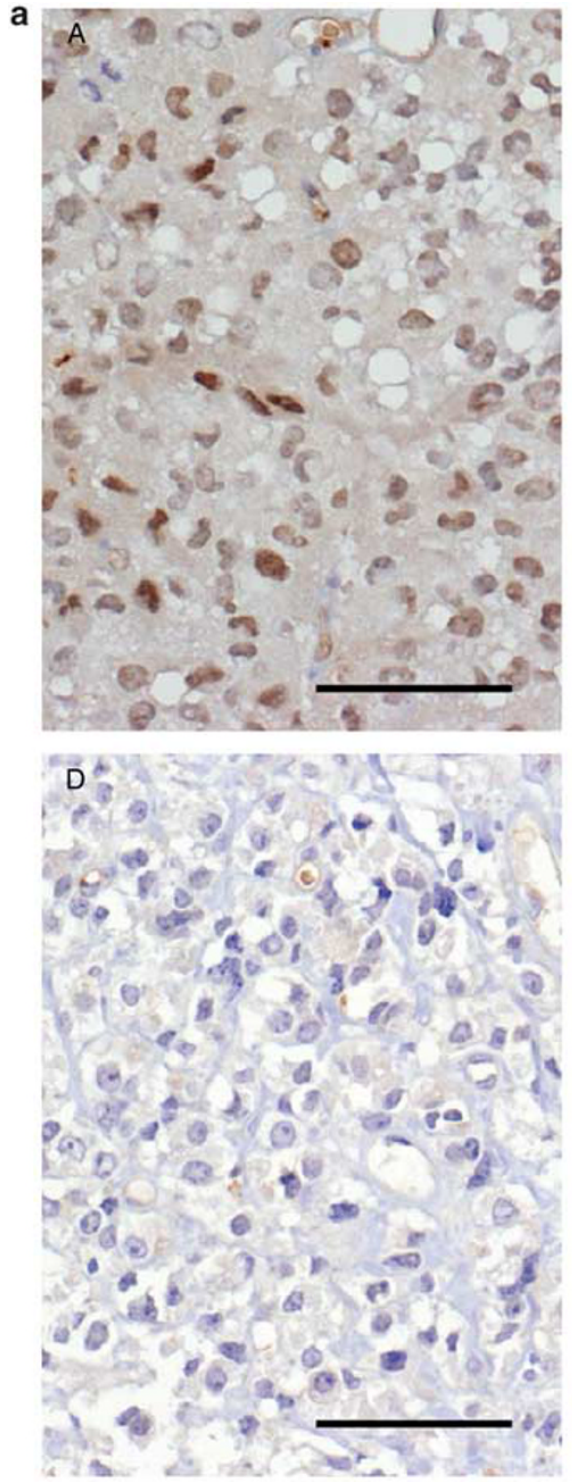
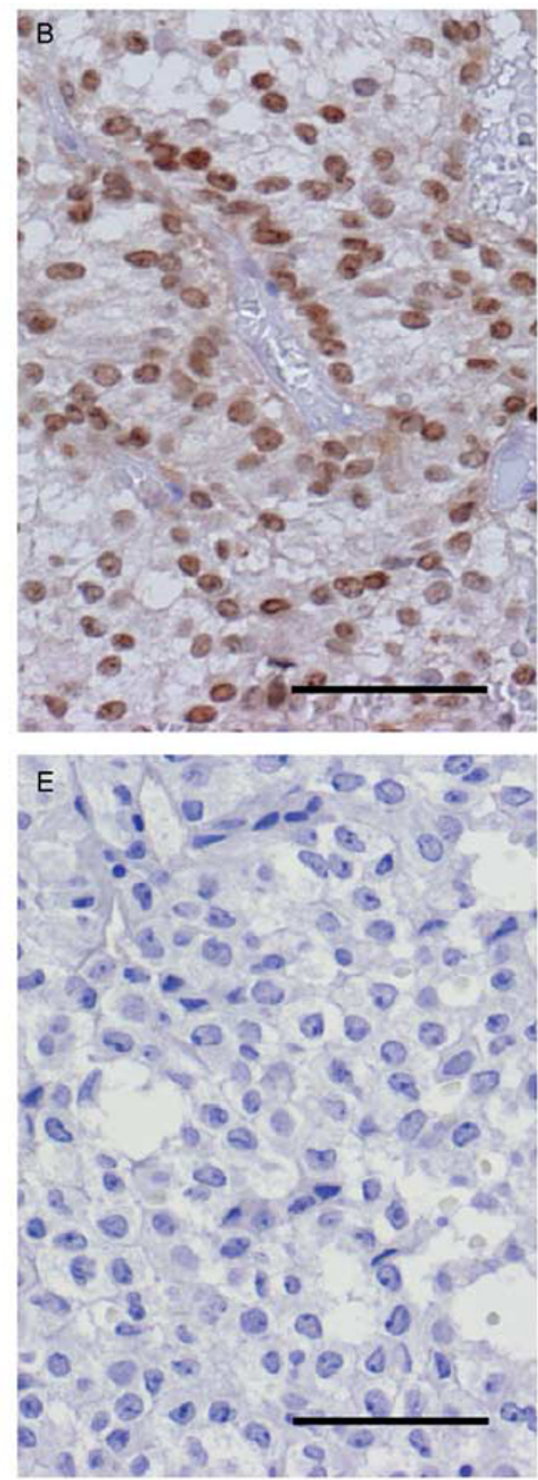
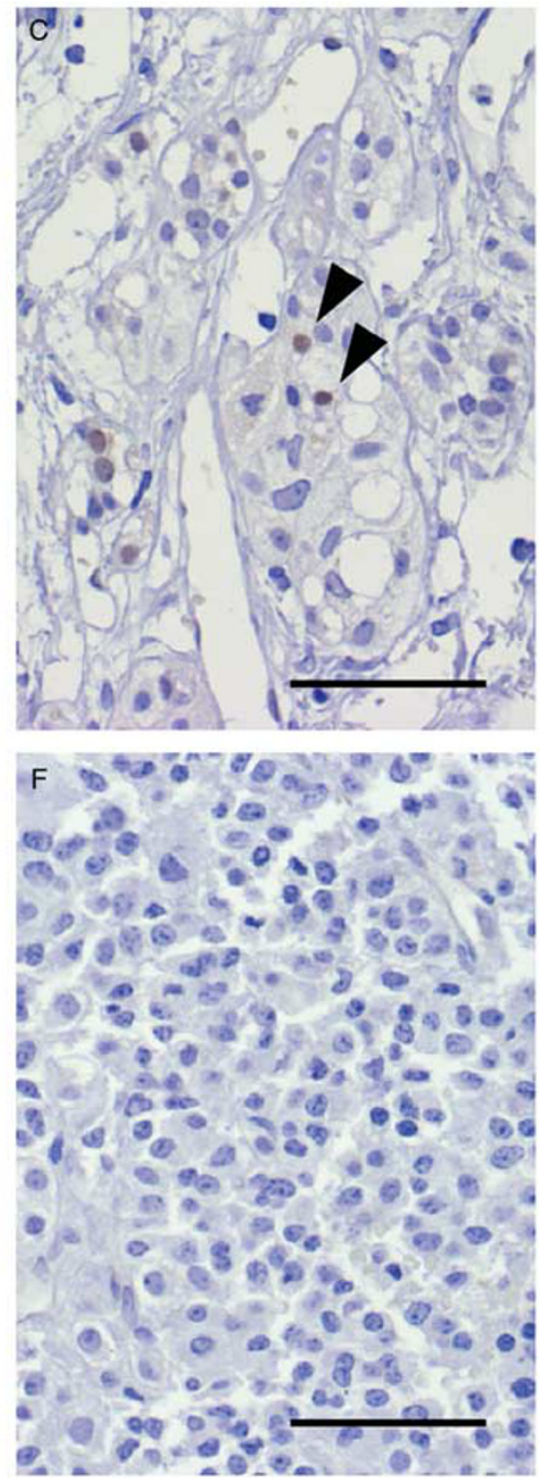

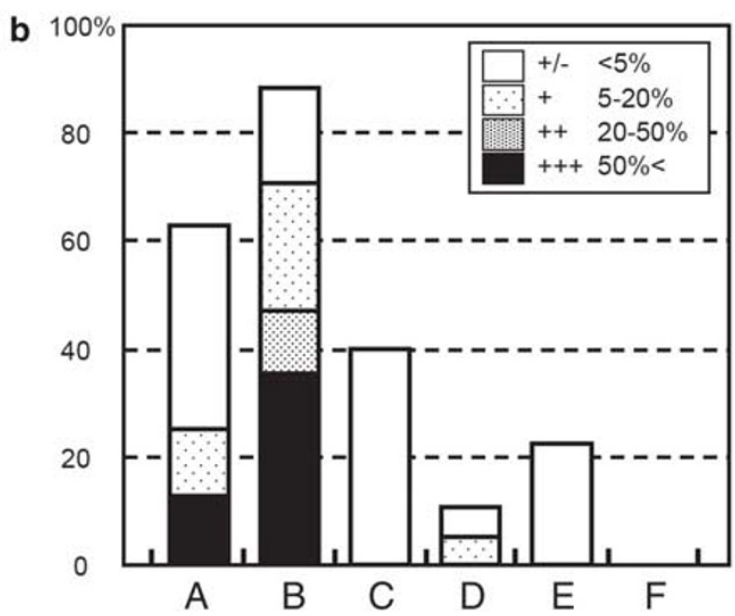

Figure 3 FOXL2 expression in pituitary adenomas. (a) FOXL2 immunoreactivity was examined in 67 human pituitary adenomas. Arrowhead, FOXL2-positive nuclei. (b) Proportions of cells displaying positive results for FOXL2 in the pituitary adenomas were compared. Null cell adenoma (A), gonadotropin-subunit-positive adenoma (B) have diffuse and strong nuclear reactivity for FOXL2 protein. FOXL2 immunoreactivity was observed in (A) null cell adenomas and (B) gonadotropin-subunit-positive adenomas. Some weakly positive $(+/-)$ cells for FOXL2 were observed in (C) TSH-producing adenomas. FOXL2 was occasionally expressed in (D) GH-producing adenomas, (E) PRL-producing adenomas, but not in (F) ACTH-producing adenomas. Bar, $50 \mu \mathrm{m}$. 


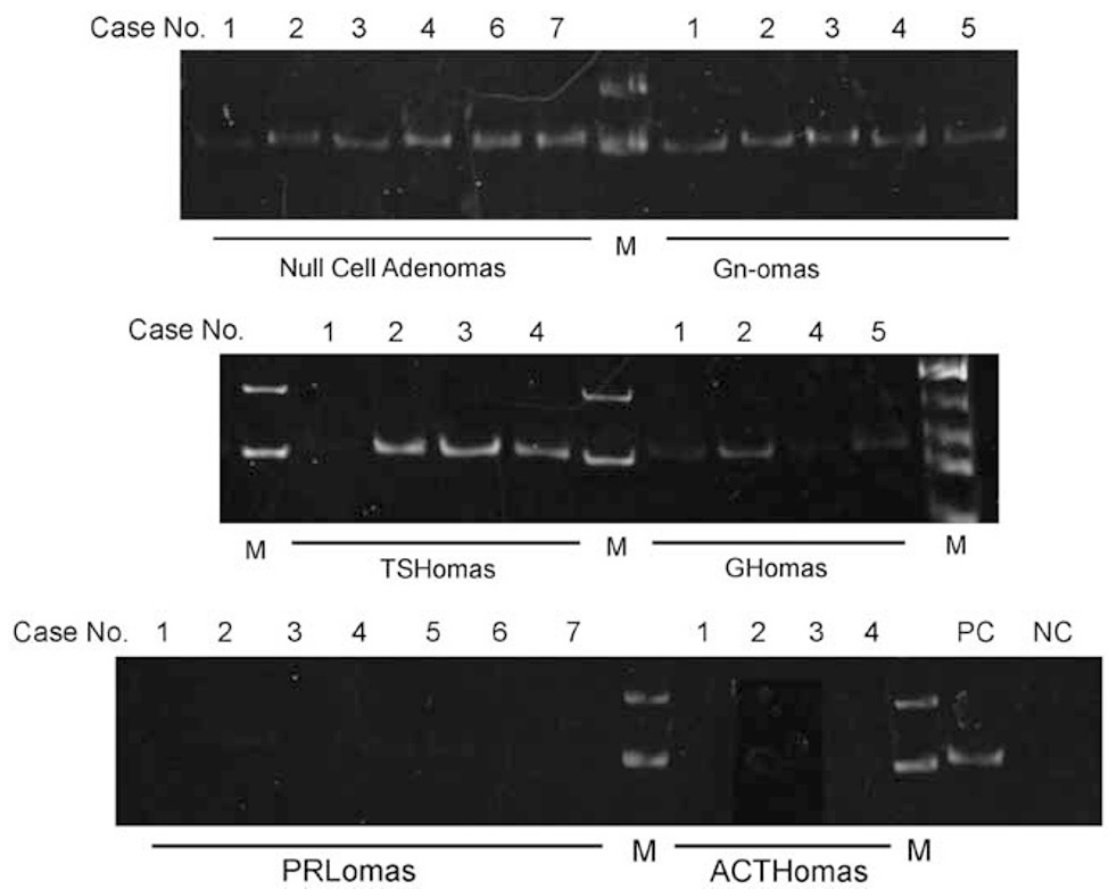

Figure 4 The expression of FOXL2 mRNA was detected in pituitary adenomas using RT-PCR. M, marker; PC, cDNA from normal human pituitary as positive control; NC, sterile water as negative control.

IHC (Figure 4). FOXL2 mRNA was detected in all six null cell adenomas, all 5 Gn-omas, 3 of 4 TSHomas, and 3 of 4 GHomas, but was not detected in all 7 PRLomas or in all 4 ACTHomas.

\section{Discussion}

Several transcription-regulating proteins have been identified in the anterior pituitary and have been implicated as key elements in the determination of cell-specific phenotypes and the regulation of hormone gene expression. In pituitary adenomas, transcription factors also regulate various genes that have important roles in functional differentiation. $^{21,22}$ FOXL2, a Fox (forkhead box) gene transcription factor that maps to the BPES locus on chromosome 3q22-23, is expressed during embryonic development and participates in terminal differentiation. FOXL2 is mutated in BPES, which is characterized by eyelid malformations, and POF. ${ }^{18}$ Mutations in individuals with BPES type I create premature stop codons in FOXL2, presumably producing a truncated protein lacking the carboxyl terminus. In the mouse, expression is observed in the perioptic mesenchyme, developing eyelids, ovary, and pituitary. Foxl2 co-localizes with the glycoprotein hormone, $\alpha \mathrm{GSU}$, in quiescent cells of the mouse pituitary from E11.5 through adulthood, suggesting a possible role in suppressing cell proliferation and/or promoting cell differentiation. $^{20}$ In mouse and porcine pituitary cells, the role of Foxl2 is related to Activin A-regulated Fsh $\beta$ transcription. ${ }^{23}$
Human FOXL2 is highly homologous to mouse Foxl2 with 90\% sequence identity and 95\% similarity at the protein level. Within the DNA-binding domain of FOXL2, there is $100 \%$ similarity at the protein level, suggesting similar promoter recognition between the two species. ${ }^{18}$ Most human pituitary adenomas are monoclonal in origin, and various transcription factors, such as PIT1, NEUROD1, GATA2, MSX1, and PTX1, may participate in the differentiation and functional expression of pituitary adenomas. ${ }^{24-29}$

We report that FOXL2 is expressed mainly in gonadotropes of normal pituitaries, and is observed in Gn-omas and null cell adenomas, which are derived from gonadotroph (LH/FSH producing) cells. ${ }^{30}$ Our findings suggest that FOXL2 has a role in differentiation toward gonadotropin ( $\mathrm{LH} \beta, \mathrm{FSH} \beta, \alpha \mathrm{GSU})$-producing cells in normal pituitaries. No staining was observed in GH cells or pure GHomass. A few cells are positive for FOXL2 in $\alpha$ SU-positive GHomas. This may indicate further subclassification of the GH cell population, GH $+\alpha \mathrm{GSU}$ double-positive cells, and pure GH cells. This staining characteristic is observed in pituitary adenomas, but in a less strict manner. In pituitary adenomas, the results of RT-PCR suggests that FOXL2 transcripts were not only detected in Gnomas and null cell adenomas, but also in TSHomas and GHomas. It is considered that FOXL2 expression was not sufficient for functional differentiation toward TSHomas and GHomas (Figure 5). These observations in human pituitary glands indicate that FOXL2 may have a role in gonadotroph cell differentiation and its committed cell lineages (Figure 5). Interaction between SF1 and FOXL2 is a key issue in this respect and remains to be further investigated. 


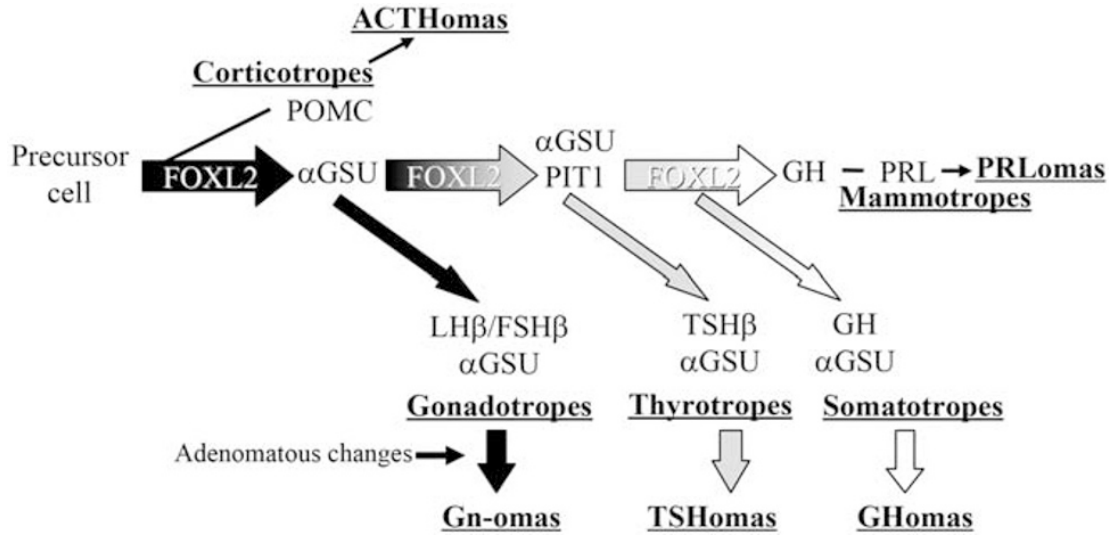

Figure 5 Schematic representation of human anterior pituitary differentiation predicted from the FOXL2 expression patterns in normal and adenomas. FOXL2 has its role in differentiation toward gonadotropin-producing cells in normal pituitaries, although it is not observed in GH cells or pure GHomas. A few FOXL2 positive cells are observed in a few cases of $\alpha$ SU-positive GHomas. FOXL2 transcripts are not only observed in Gn-omas and null cell adenomas, but also in TSHomas and GHomas. It is considered that FOXL2 expression was not enough for functional differentiation in TSHomas and GHomas. And its function may be more important to the differentiation of gonadotroph cell lineage than thyrotroph and somatotroph cell lineages.

In conclusion, FOXL2 expressing cells were confined mainly to gonadotropin-subunit-producing cells in human normal pituitaries. FOXL2 was detected in a small fraction of TSH-producing cells. FOXL2 was localized immunohistochemically in many of the gonadotroph cell adenomas. Our results suggest that FOXL2 contributes to the specific functional expression and differentiation in gonadotroph cells and in gonadotroph adenomas in humans.

\section{Acknowledgements}

We thank Dr Sally A Camper (University of Michigan Medical School) and Dr Buffy S Ellsworth (Southern Illinois University School of Medicine) for their expert advice. This work was supported by a Grant-in-Aid for Scientific Research Projects (\#193901051 and 19790270) of the Japanese Ministry of Education, Culture, Sports, Science and Technology, by the Research on Measures for Intractable Diseases Project of the HypothalamoPituitary Dysfunction Research Group of the Japanese Ministry of Health, Labor and Welfare, and by a Grant from the Tokai University School of Medicine Research Aid (2005-2007).

\section{Disclosure/conflict of interest}

The authors declare no conflict of interest.

\section{References}

1 Voss JW, Yao TP, Rosenfeld MG. Alternative translation initiation site usage results in two structurally distinct forms of Pit-1. J Biol Chem 1991;266:12832-12835.

2 Lamonerie T, Tremblay JJ, Lanctot C, et al. Ptx1, a bicoid-related homeo box transcription factor involved in transcription of the pro-opiomelanocortin gene. Genes Dev 1996;10:1284-1295.

3 Gage PJ, Suh H, Camper SA. Dosage requirement of Pitx2 for development of multiple organs. Development 1999;126:4643-4651.

4 Bach I, Carriere C, Ostendorff HP, et al. A family of LIM domain-associated cofactors confer transcriptional synergism between LIM and Otx homeodomain proteins. Genes Dev 1997;11:1370-1380.

5 Sheng HZ, Moriyama K, Yamashita T, et al. Multistep control of pituitary organogenesis. Science 1997;278: 1809-1812.

6 Gage PJ, Brinkmeier ML, Scarlett LM, et al. The Ames dwarf gene, $\mathrm{df}$, is required early in pituitary ontogeny for the extinction of Rpx transcription and initiation of lineage-specific cell proliferation. Mol Endocrinol 1996;10:1570-1581.

7 Lamolet B, Pulichino AM, Lamonerie T, et al. A pituitary cell-restricted $\mathrm{T}$ box factor, Tpit, activates POMC transcription in cooperation with Pitx homeoproteins. Cell 2001;104:849-859.

8 Tremblay JJ, Viger RS. GATA factors differentially activate multiple gonadal promoters through conserved GATA regulatory elements. Endocrinology 2001;142:977-986.

$9 \mathrm{Li}$ LA, Lala D, Chung BC. Function of steroidogenic factor 1 (SF1) ligand-binding domain in gene activation and interaction with AP1. Biochem Biophys Res Commun 1998;250:318-320.

10 Suh H, Gage PJ, Drouin J, et al. Pitx2 is required at multiple stages of pituitary organogenesis: pituitary primordium formation and cell specification. Development 2002;129:329-337.

11 Simmons DM, Voss JW, Ingraham HA, et al. Pituitary cell phenotypes involve cell-specific Pit-1 mRNA translation and synergistic interactions with other classes of transcription factors. Genes Dev 1990;4:695-711.

12 Lipkin SM, Naar AM, Kalla KA, et al. Identification of a novel zinc finger protein binding a conserved element critical for Pit-1-dependent growth hormone gene expression. Genes Dev 1993;7:1674-1687.

13 Kalinichenko VV, Gusarova GA, Shin B, et al. The forkhead box F1 transcription factor is expressed in brain and head mesenchyme during mouse embryonic development. Gene Expr Patterns 2003;3:153-158. 
14 Dathan N, Parlato R, Rosica A, et al. Distribution of the titf2/foxe1 gene product is consistent with an important role in the development of foregut endoderm, palate, and hair. Dev Dyn 2002;224:450-456.

15 Richards JS, Sharma SC, Falender AE, et al. Expression of FKHR, FKHRL1, and AFX genes in the rodent ovary: evidence for regulation by IGF-I, estrogen, and the gonadotropins. Mol Endocrinol 2002;16:580-599.

16 Chen G, Nomura M, Morinaga H, et al. Modulation of androgen receptor transactivation by FoxH1. A newly identified androgen receptor corepressor. J Biol Chem 2005;280:36355-36363.

17 Uda M, Ottolenghi C, Crisponi L, et al. Foxl2 disruption causes mouse ovarian failure by pervasive blockage of follicle development. Hum Mol Genet 2004;13:1171-1181.

18 Crisponi L, Deiana $\mathrm{M}$, Loi $\mathrm{A}$, et al. The putative forkhead transcription factor FOXL2 is mutated in blepharophimosis/ptosis/epicanthus inversus syndrome. Nat Genet 2001;27:159-166.

19 Kioussi C, O’Connell S, St-Onge L, et al. Pax6 is essential for establishing ventral-dorsal cell boundaries in pituitary gland development. Proc Natl Acad Sci USA 1999;96:14378-14382.

20 Ellsworth BS, Egashira N, Haller JL, et al. FOXL2 in the pituitary: molecular, genetic, and developmental analysis. Mol Endocrinol 2006;20:2796-2805.

21 Lloyd RV, Osamura RY. Transcription factors in normal and neoplastic pituitary tissues. Microsc Res Tech 1997;39:168-181.
22 Mullis PE. Transcription factors in pituitary gland development and their clinical impact on phenotype. Horm Res 2000;54:107-119.

23 Lamba P, Fortin J, Tran S, et al. A novel role for the forkhead transcription factor FOXL2 in activin Aregulated follicle-stimulating hormone beta subunit transcription. Mol Endocrinol 2009;23:1001-1013.

24 Sanno N, Teramoto A, Matsuno A, et al. In situ hybridization analysis of Pit-1 mRNA and hormonal production in human pituitary adenomas. Acta Neuropathol 1996;91:263-268.

25 Miyai S, Yoshimura S, Iwasaki Y, et al. Induction of GH, PRL, and TSH beta mRNA by transfection of Pit-1 in a human pituitary adenoma-derived cell line. Cell Tissue Res 2005;322:269-277.

26 Fratticci A, Grieco FA, Spilioti C, et al. Differential expression of neurogenins and NeuroD1 in human pituitary tumours. J Endocrinol 2007;194:475-484.

27 Oyama K, Sanno N, Teramoto A, et al. Expression of neuro D1 in human normal pituitaries and pituitary adenomas. Mod Pathol 2001;14:892-899.

28 Umeoka K, Sanno N, Osamura RY, et al. Expression of GATA-2 in human pituitary adenomas. Mod Pathol 2002;15:11-17.

29 Mizokami Y, Egashira N, Takekoshi S, et al. Expression of MSX1 in human normal pituitaries and pituitary adenomas. Endocr Pathol 2008;19:54-61.

30 Chaidarun SS, Klibanski A. Gonadotropinomas. Semin Reprod Med 2002;20:339-348. 